\title{
The Important Role that Cultural Heritage Plays in a Life of a Nation and Its Sanction in the Universal Declaration of Human Rights
}

\author{
Msc. Erjona Hasa (Phd Candidate) \\ "Aleksandër Xhuvani" University, Faculty of Educational Sciences, Department of Civic Education \\ Email: hasaerjona@gmail.com
}

Doi:10.5901/ajis.2015.v4n3s1p430

\section{Problem Overview}

Cultural and natural heritage is one of the most precious assets of our world and artistic tradition created by the man. It is sanctioned in Article 22 of the Universal Declaration of Human rights.

Heritage is dedicated to the recognition and popularization of the tradition and distinctive values created by nature and mankind over the years. For this reason cultural and natural heritage links in a single unit human and natural values created in the world with those created in Albania. Therefore, becomes tangible the capital importance of appreciation of these values in terms of historical, cultural, geographical and environmental point of view.

Cultural heritage has two basic divisions: the material and spiritual heritage. Cultural heritage is the artistic and cultural production that is selected and assessed only by time. An Integral part of cultural heritage is also natural heritage. Natural heritage and landscape are estimated to have the same value equivalent to cultural heritage. Landscape itself plays an important public role in the formation of cultures in every environment and that these cultures have served and serve as the basic component of the European heritage and consolidation of the European Identity.

Cultural heritage is the wealth of generations, our major obligation toward our past and future, material and spiritual continuity of a nation. As such, cultural heritage is a constant challenge facing state care, to keep track of the age-old creative genius and to convey it to the future. Albanian Cultural heritage is a heritage enriched in values. It includes archeological, urban, architectural, historical and engineering values. It also includes movable heritage, archeological sites, monuments, books and documents, numismatics, almise and firearms, artistic artifacts and rare items. Spiritual heritage includes language, oral folklore and music of all genres, traditions and beliefs of all kinds and handicrafts.

\section{The Purpose and Objectives of the Study}

The purpose of the study is to show the precious values and the role that cultural heritage plays in our lives. The major objective of this paper consists in the promotion and dissemination of cultural heritage of our country, stimulating broader educational activities related to its historical values as the first priority, including all national and international educative and scientific mechanisms.

Cultural and natural heritage of outstanding beauty and artistic values, of its diverse kinds and important cultural and natural monuments, in its essence includes education of a civic European culture and meanwhile it helps to create a personality as citizens of the world. Heritage, in addition to other things, affects the creation of the cultural identity feeling, in the growth of respect and in the promotion of the values of cultural heritage, in the integration of our heritage in the contemporary lives of Albania and Albanians as well as in commemoration of a work and lives of the outstanding personalities of the heritage and to all others anonymous artists who created these values over years. The aim is to have a correct perception of the national identity at the same time.

Through this study we will understand that heritage will serve to deepen our knowledge that will lead to interconnect theory and its values with its characterization in practice as well as in relation with tourism, environment and legal education related to this field.

\section{Methodology}

The methodology employed in this paper is qualitative research, related to the research of the national and international legislation, aiming at the unification with EU law and bringing the highest legislative standards that regulates the relations 
between monuments and state.

The first strategic step regarding monuments is the definition of a new philosophy that naturally intertwines the current enriched Albanian experience with the highest internationally recognized achievements and standards. Monuments will no longer be seen as an amorphous thing in itself, but as an integral part of cultural tourism and economic development of the country.

\section{Findings and Recommendations}

- Constant improve of legislation, aiming legal unification with the EU countries, thus bringing higher standards and achievements of legislation that regulates the relations between monuments, government and community, relationships that until now were not properly structured, related to responsibilities and benefits.

- All monuments are not completed without scientific documentary, which means providing all monuments with accurate technical-scientific passports, which will summarize all important achieved data, given the high standards provided by international organizations related to monuments.

- Thorough restructuring of activities of institutions legally responsible for the protection and management of monuments.

- The creation of more flexible structures which provide optimal territorial coverage; the creation of efficient structures to ensure not only protection, but also a beneficial management of monuments; the creation of modern structures that ensures optimal coordination between central and local governing institutions, local communities and civil society organizations. The right coordination of these relationships will ensure a greater interaction related to monuments.

- Scientific reforming of state institutions responsible for the heritage enables the creation of a new generation of architecture and art restorers, as well as improving current restorers' technological knowledge, promoting their training and qualification.

- Involvement of local communities as partners in decision-making process for monuments, seeking their contribution in the revitalization process of monuments and their involvement in socio-economic life of communities.

- Increased funding to protect monuments, a step that would be seen as inseparable from increased cooperation with international partners, donors and individuals.

- Cooperation between the restorers and archeologists is seen as a necessary prerequisite to increase the impact of institutional activities. New archeological excavation should be planned jointly to prevent any kind of damage or lack of attention.

- In addition to propagation, another priority is seen a broad educational activity related to the values of our heritage, including all educational and scientific mechanisms in the country in a joint initiative.

- Field care for monuments and their protection, especially from the abuses committed by human, is one of the most strategic step that has attracted and attracts the attention of institutions, by monitoring in details all violations committed to the monuments, identifying all these violation and taking appropriate technical and legal measures that not only avoid mistakes of the past but do not create space for future violations. To avoid possible violations and to repair the violations committed, the cooperation with the police department of construction would ensure an effective protection.

\section{References}

Kuri,V: The Albanian Tradition and customary law .

The Universal Declaration of human rights.

The law no.9048, date 07.04.2003 " For cultural heritage ", disorted.

The Convention for heritage and cultural materials.

Riza, Emin : The Folk architecture and its evaluation.

Feilden, Bernard, Jokilehto, Jukka : The guideline for world cultural heritage management. 